\title{
Low Intensity Training Provokes Adaptations on Muscle Fibrosis of a Muscular Dystrophy Model
}

\author{
El Entrenamiento de Baja Intensidad Provoca Adaptaciones en la \\ Fibrosis Muscular de un Modelo de Distrofia Muscular \\ Priscilla Avelino Ferreira Pinto ${ }^{1}$; Alex Sander Dias Machado ${ }^{2}$; Lívia Rocha Libório ${ }^{3}$; \\ Ana Paula Santos ${ }^{1}$; Murilo Xavier Oliveira ${ }^{1} \&$ Thaís Peixoto Gaiad ${ }^{1}$
}

PINTO, P. A. F.; MACHADO, A. S. D.; LIBÓRIO, L. R.; SANTOS, A. P.; OLIVEIRA, M. X. \& GAIAD, T. P. Low intensity training provokes adaptations on muscle fibrosis of a muscular dystrophy model. Int. J. Morphol., 36(2):471-477, 2018.

SUMMARY: Duchenne muscular dystrophy (DMD) is a genetic neuromuscular disorder with progressive clinical signs until death, around the second decade of life. Mdx is the most used animal model to pre-clinical studies of DMD. Parameters of exercise on this muscular disease are still unknown. This research aimed to investigate if the low intensity treadmill training would exacerbate the markers of muscle injury, fibrosis, and the composition of the extracellular matrix by type I and III collagens of the mdx model. Dystrophic 11-week-old male mice were separated in exercised $(\mathrm{mdxE}, \mathrm{n}=8)$ and sedentary $(\mathrm{mdxC}, \mathrm{n}=8)$ groups. Wild-type mice were used as control (WT, n=8). Exercised group underwent a LIT protocol (9 m/min, 30min, 3days/week, 60 days) on a horizontal treadmill. Gastrocnemius muscle was collected at day 60 and processed to morphological and morphometric analyzes. Sedentary mdx animals presented inflammatory infiltrate and necrotic fibers. Histochemical analysis revealed that the perimysium of the mdxC group is organized into thick and clustered collagen fibers, which generates a larger area of intramuscular collagen fibers for these animals. Histomorphometry attested that fraction area of collagen fibers of $\mathrm{mdxC}$ group was higher than $\mathrm{mdxE}$ group $(\mathrm{p}=0.04)$ and mdxE group values similar to WT group $(\mathrm{p}=1.00)$. Centrally located nuclei fibers and the variance coefficient $(\mathrm{VC})$ of minimal Feret's diameter was similar in mdxE and $\operatorname{mdxC}$ groups $(\mathrm{p}=1.00)$ and both groups presented higher mean values than WT group $(\mathrm{p}<0.00)$. Immunohistochemistry revealed the presence of type I collagen mainly in the $\mathrm{mdxC}$ group. LIT protocol had not exacerbated muscle injuries resulting from the dystrophindeficiency membrane fragility at the same time that had reduced the intramuscular collagen deposition. LIT had positively influenced these markers of dystrophic muscle injury on gastrocnemius muscle of mdx model.

KEY WORDS: Duchenne muscular dystrophy; Exercise; Skeletal muscle; Collagen.

\section{INTRODUCCIÓN}

Duchenne Muscular Dystrophy (DMD) is a progressive, $\mathrm{X}$-linked recessive genetic disease that affects 1: 3500 male births. DMD is marked by the lack of dystrophin, the major protein of the dystrophinglycoprotein complex (Nakamura \& Takeda, 2011; Hyzewicz et al., 2015).

The absence of dystrophin leads to mechanical changes in muscle fiber, as repetitive cycles of degeneration and regeneration, resulting in high percentage of myofibers with central nucleus; fiber size heterogeneity and fragmented sarcolemma (Briguet et al., 2004; Mann et al., 2011; Nakamura \& Takeda). In addition, there is an aberrant repair of the muscle tissue that is gradually replaced by muscle fibrosis as a result of a chronic inflammatory response (Mann et al.; Holland et al., 2016). Muscular fibrosis has functional consequences such as increased muscle stiffness and reduced functionality (Smith \& Barton, 2014; Serrano \& Muñoz-Cánoves, 2017). The main collagen fibers in muscle tissue are collagen fibers type III, mainly located at perimysium and Type I, more present in endomysium (Mackey et al., 2005; Holland et al.).

\footnotetext{
${ }^{1}$ Department of Physical Therapy, Universidade Federal dos Vales do Jequitinhonha e Mucuri, UVJM, Brazil.

${ }^{2}$ Faculty of Medicine, Universidade Federal dos Vales do Jequitinhonha e Mucuri, UVJM, Brazil.

${ }^{3}$ Department of Nursing, Universidade Federal dos Vales do Jequitinhonha e Mucuri, UVJM, Brazil.

FAPEMIG (Minas Gerais State Agency for Research and Development) supported this research by the process n ${ }^{\circ}$ APQ-01971-12 and the Master degree scholarship of the first author. The funders had no role in study design, data collection and analysis, decision to publish or preparation of the manuscript.
} 
The natural progression of the disease leads to progressive muscle weakness, loss of ambulation ability around 12 years old, cardiorespiratory complications and death around the second or thirty decade of life. Physical therapy acts in a multidisciplinary way aiming to give supportive therapy to these patients. However, it is uncertain if exercise is beneficial or deleterious to skeletal dystrophic muscle (Gianola et al., 2013) once the absence of dystrophin leads the muscle fiber susceptible to exerciseinduce injury (Mann et al.).

The most used animal model for pre-clinical studies of DMD is the mdx mouse (Manning \& O'Malley, 2015; Hyzewicz et al., 2015). The mdx mouse shows absence of dystrophin and has genetic and biochemical homology to humans DMD but its phenotype is considered mild (Manning \& O’Malley).

Trying to elucidate the best frequency, type and modality of exercise for DMD, the mdx mouse has been used to attest the effects of different modalities such as swimming, voluntary wheel running, Rota-rod ${ }^{\circledR}$ and motorized treadmill (Hyzewicz et al., 2015). These studies have brought some insight of what should, or should not be applied to skeletal dystrophic muscle but there is not a consensus once major of them use a high intensity training that exacerbates the progression of the disease and attest the efficacy of some method of intervention.

The objective of this study was to investigate if the low intensity treadmill training would exacerbate the morphological features such as markers of muscle injury, fibrosis, and the composition of the extracellular matrix by Type I and III collagens of the mdx model.

\section{MATERIAL AND METHOD}

Sixteen male dystrophic mdx mice (C57BL/10ScSnDmdmdx/J) and controls wild-type (C57BL/10) acquired from Fiocruz Institute (Rio de Janeiro, RJ, Brazil) were used in this study. Animals were maintained in cages on a $12 \mathrm{~h}$ day $/ 12 \mathrm{~h}$ dark cycle with ambient temperature controlled at $22{ }^{\circ} \mathrm{C}$ and supplied with food and water ad libitum. The mdx mice were randomized into two groups: Exercised group ( $\mathrm{mdxE}, \mathrm{n}=8$ ) and Sedentary group $(\mathrm{mdxC}, \mathrm{n}=8)$. A control group was composed by wild-type mice and denominated WT $(n=8)$. At the beginning of the exercise protocol, animals were 11 weeks old. The age of 8 to 12 weeks is considered a morphological stable phase of the disease once animals have already suffered an important cycle of degenerationregeneration. Also, at this age there is an already described similarity of fibrosis and muscular deterioration between humans and mdx mice age-matched. See schematic Figure 1 plotted with these similarities between both species according to the literature (Briguet et al.; Grounds et al., 2008; Barnabei et al., 2011; Hyzewicz et al., 2015). This research was approved by the Ethics Committee on Animal Use of the University Federal dos Vales do Jequitinhonha e Mucuri (CEUA/UFVJM), protocol number 017/2011.

Training protocol. Animals of mdxE group underwent a low-intensity training (LIT) protocol on a horizontal treadmill (EP 131; Insight $®$, Brazil) 30 min/day, 3 times a week for 8 weeks at a velocity of $9 \mathrm{~m} / \mathrm{min}$. The speed was controlled at $9 \mathrm{~m} / \mathrm{min}$ so the protocol was considered of low intensity (Kacsor et al., 2007). Before the experimental period, animals underwent a period of adaptation in order to familiarize with the treadmill and speed, which was gradually increased between the sessions. Animals of the mdxC and WT group were sedentary and exposed to the same variations of illumination and noise level.

Skeletal Muscle Collection. Twenty four h after the final exercise session, all animals were subjected to an overdose of ketamine hydrochloride $(200 \mathrm{mg} / \mathrm{kg})$ and xylazine hydrochloride $(20 \mathrm{mg} / \mathrm{kg})$, via intraperitoneal injection (CEUA protocol $\mathrm{n}^{\circ} 017 / 11$ ). The lateral gastrocnemius muscle (GAS) of the pelvic right limb were collected and fixed in paraformaldehyde solution at $4 \%$.

Histological and histochemical analysis. Muscle samples were treated with increasing ethanol concentrations (70 to $100 \%$ ) to dehydrate and with xylene to clear. The samples were then embedded in paraffin (Ervplast $\left.{ }^{\circledR}\right)$ and sections of $5 \mu \mathrm{m}$ in thickness were obtained. The cross-sections were oven-dried $\left(60{ }^{\circ} \mathrm{C}\right)$ at a horizontal position for better adhesion of the cuts. After deparaffinization protocol, the sections were stained using Hematoxylin-eosin (HE) to identify histopathological features. Histochemical reaction using Picrossirius red, a combination of Sirius red F3BA (Sigma-Aldrich, Colour Index 35780) dissolved in a saturated picric acid solution, was used in order to distinguish collagen from the skeletal muscle fibers. Photomicrographs were made under an optical microscope (LABOMED® LxPol) equipped with an Axio CAM HRc camera and Software Capture Pro 2.9.0.1.

\section{Centrally located nuclei (CLN) quantification.} Photomicrographs of the HE slides were performed in 100x, sequentially, in different fields, not overlapping and the images were analyzed using Image $₫$ software. 2000 muscle fibers per animal were analyzed to determine the percentage of muscle fibers that presented CLN in relation to total fibers (Dubach-Powell et al., 2014). 
Minimal Feret's diameter (MFD) quantification. The minimal Feret's diameter is the minimum distance of parallel tangents at opposing margins of the muscle fiber (Briguet et al.). The variance coefficient (VC) of the minimal Feret's diameter (MFD) was determined from HE stained sections from 400x images from the muscle samples with integrity of sarcolemma. $\mathrm{VC}$ of a minimum of 100 muscle fibers per animal (de Brito et al., 2006) was analyzed using ImageJ ${ }^{\circledR}$ software.

Intramuscular collagen fiber quantification. Slides reacted with picrosirius red were analyzed under polarized light in 100x. Photomicrographs of $\sim 5$ sequential images of each animal studied were performed to carry out the analysis of the whole section transverse muscle (Smith \& Barton). The amount of deposition of the collagen fibers was calculated by the percentage of the area of collagen fibers in relation to the total area $\left(964819.05 \mu \mathrm{m}^{2}\right)$ of each image, through binary analysis (black/white) and expressed in micrometers using Image ${ }^{\circledR}$ software.

Immunohistochemistry analysis (IHC). Primary polyclonal antibodies against collagen (anti-mouse) types I and III (Abcam $\left.{ }^{\circledR}\right), 1: 100$ and 1:250 dilution were applied on the muscle sections, separately. Sections were immersed in citric acid solution at $0.01 \mathrm{M}, \mathrm{pH} 6.0$ and submitted to $95^{\circ} \mathrm{C}$ for 30 min to antigenic recovery. Next, the blockade of endogenous peroxidase with hydrogen peroxide at $3 \%$ for $40 \mathrm{~min}$ was performed. Primary antibodies were applied and incubated for $20 \mathrm{~h}$ in a damp chamber at $4{ }^{\circ} \mathrm{C}$. After three more rinses in buffered saline solution (PBS), secondary antibody ( $\mathrm{N}$-Histofine $\left.{ }^{\circledR}\right)$ was applied and incubated for $30 \mathrm{~min}$ at room temperature $\left(24^{\circ} \mathrm{C}\right)$. IHC reaction was revealed with DAB (Chromogen/Substrate Bulk Pack, ScyTek Laboratories) for $2 \mathrm{~min}$. In the negative control, the primary antibody was omitted and all slides were counterstained with hematoxylin.

Data analysis. Qualitative assessments of histological, histochemical and IHC of muscle samples were analyzed by observing three sections from each of the animals $(\mathrm{n}=$ 8) per group (3). The descriptive statistical analysis was performed via mean and standard deviation calculations (CLN quantification, VC of MFD and intramuscular collagen fiber quantification). Analysis of the normality of the data was performed by the Shapiro-Wilk test and considering normal distribution the $\mathrm{p}$ value $>0.05$. To detect difference between groups the analysis of variance (ANOVA) was performed and the Bonferroni test was used as post hoc. The IBM SPSS Statistics ver. 22.0 (IBM Co., Armonk, NY, USA) was used with the level of significance set at $\mathrm{p}<0.05$.

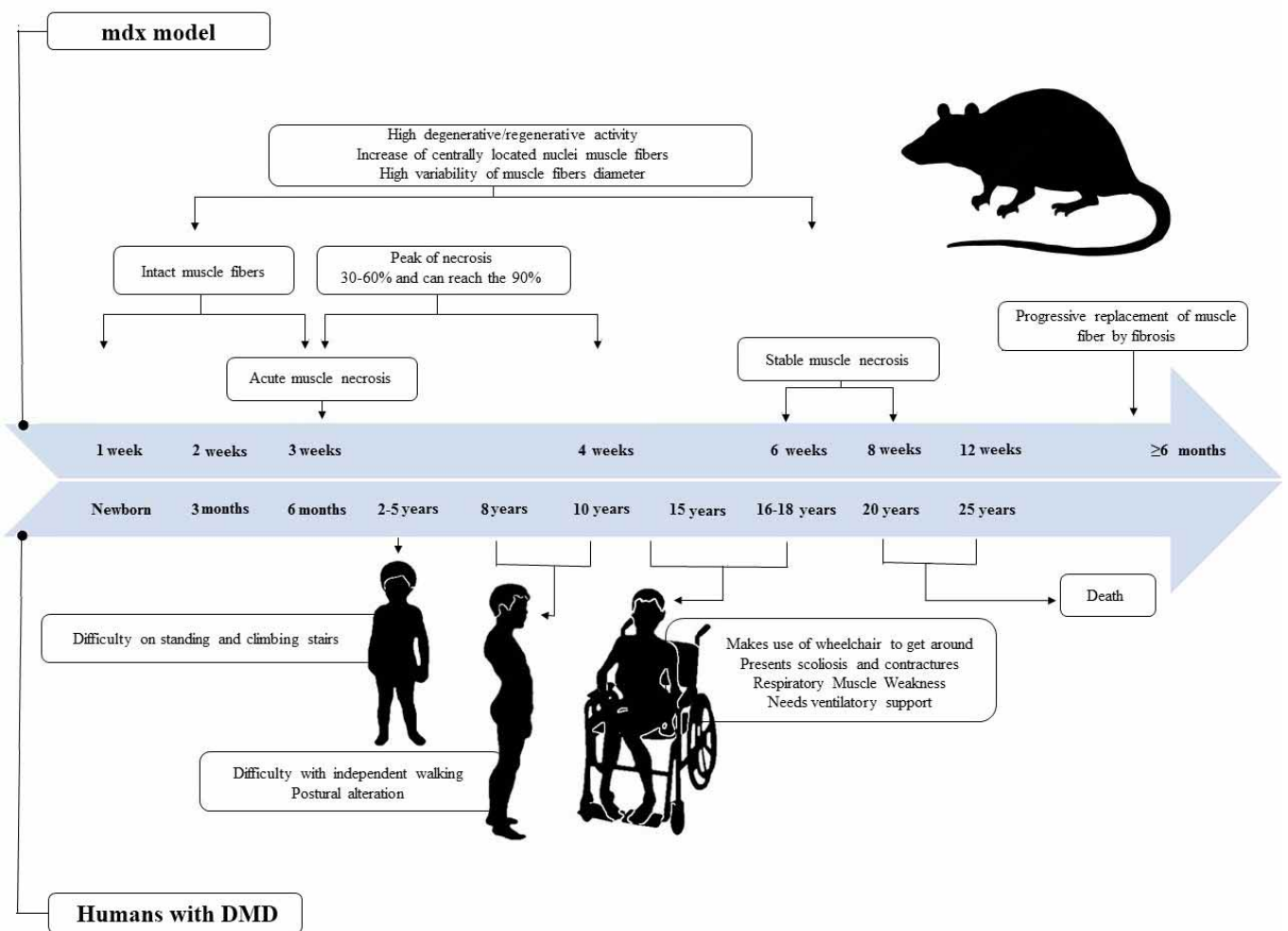

Fig. 1. Scheme detailing the pelvic limb muscle degeneration progression and its relation between humans DMD and the mdx mice model. Adapted from Briguet et al. (2004), Grounds et al. (2008) Barnabei et al. (2011) and Hyzewicz et al. (2015). 


\section{RESULTS}

Qualitative analysis showed the presence of heterogeneity and centrally located nuclei of muscle fiber from mdxE and mdxC groups (Fig. 2A-C). Animals of mdxC group also presented necrotic fibers and inflammatory infiltrate (Fig. 2B). MdxE (65.3 $\pm 6.9 \%)$ and $\mathrm{mdxC}(62.9 \pm 7.2$ $\%$ ) animals showed similar values of fiber with CLN in relation to the total number of fibers $(\mathrm{p}=1.00)$. These both groups presented higher CLN fibers than WT group (2.2 \pm 0.9 $\%)(\mathrm{p}<0.00)$ (Fig. 3A). This same behavior was observed to the VC of the MFD: $\mathrm{mdxE}(345.8 \pm 44.3)$ and $\mathrm{mdxC}$ (343.1 \pm 34.4$)$ presented similar heterogeneity of their miofibers $(\mathrm{p}=1.00)$ and higher variability than WT group $(207.8 \pm 29.5)(\mathrm{p}<0.00)($ Fig. 3B).

The collagen fibers are organized in thick tracts in the perimysium and thin bundles in the endomysium of all dystrophic animals, exercised or sedentary. Collagen fibers of WT animals are organized in thin tracts at perimysium and endomysium (Fig. 4A-C). The perimysium of the $\mathrm{mdxC}$

\section{$m d x \mathbf{E}$}

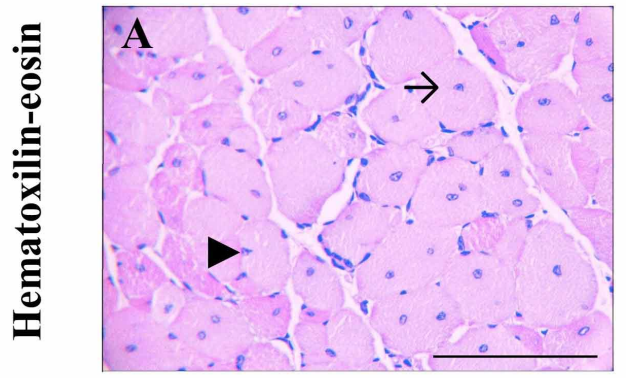

$m d x \mathrm{C}$

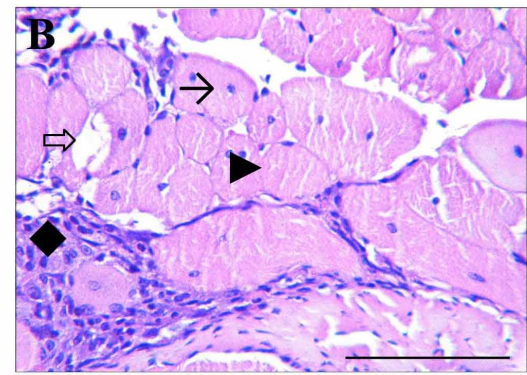

WT

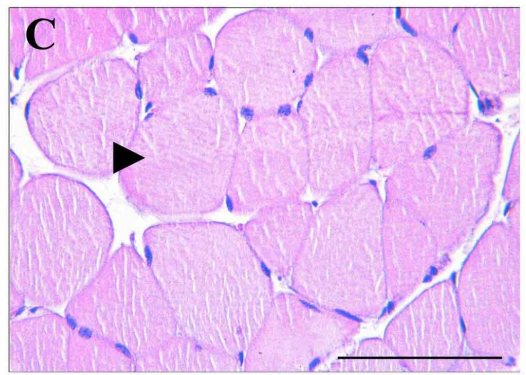

Fig. 2. Morphological analysis of gastrocnemius muscles of mdxE, mdxC and WT groups at 60 days of LIT protocol, 400x, HE staining; $\boldsymbol{\nabla}$ heterogeneity of muscle fibers, $\rightarrow$ centrally located nuclei, $\bullet$ inflammatory infiltrate and $\Rightarrow$ necrosis. Bar $=100 \mu \mathrm{m}$.

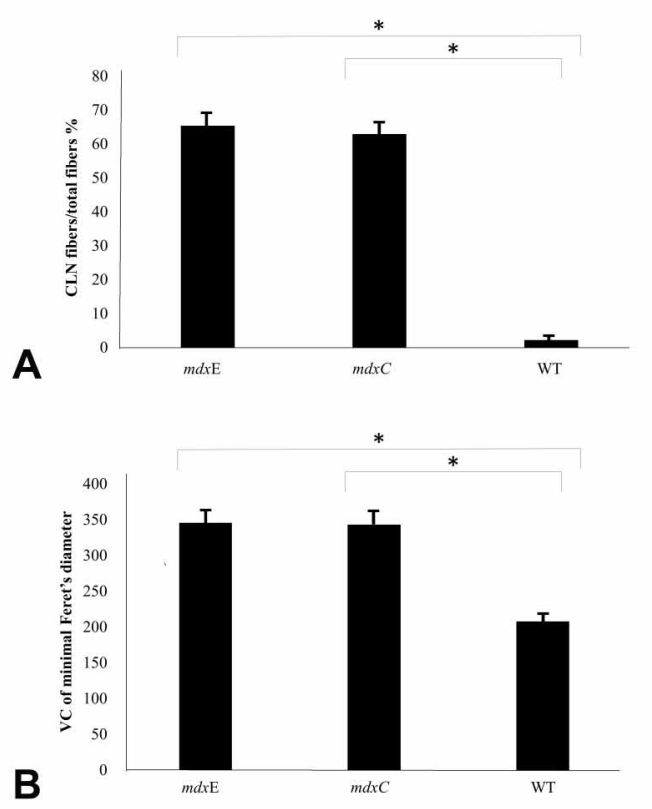

Fig. 3. Percentage of muscle fibers with centrally located nuclei (CLN) (A) and VC of Minimal Feret's Diameter (MFT) (B). Mean values of $\mathrm{mdxC}$ and $\mathrm{mdxE}$ are statistically different from mean values of WT groups in both graphics. *Mean values are statistically different at $5 \%$ attested by Anova, post-hoc Bonferroni. group is organized into thick and clustered collagen fibers, which generates a larger area of intramuscular collagen fibers for these animals (Fig. 4B). The percentage area of intramuscular collagen fibers deposition of $\mathrm{mdxC}$ group was higher $(4.2 \pm 3.3)$ than $\operatorname{mdxE}(1.7 \pm 0.9)(\mathrm{p}=0.04)$ and WT $(1.1 \pm 1.1)(\mathrm{p}=0.03)$ groups (Fig. 5).

Collagen fibers type I are located at perimysium and collagen fibers type III at endomysium and perimysium of WT (Fig. 6). On dystrophic animals, Collagen type I is located also at endomysium (Fig. 6B) staining thicker tracts on $\mathrm{mdxC}$ group.

\section{DISCUSSION}

Dystrophic muscle is susceptible to injury-induced by exercise training and the effects of physical training on muscle fiber morphology are still controversial (Gianola et al.; Hyzewicz et al., 2015). Most studies that have analyzed the treadmill training on mdx mice model used a high intensity of training. This high intensity treadmill training has shown deleterious effects on dystrophic muscle such as higher amount of muscle injury area (Capogrosso et al. 2017), 

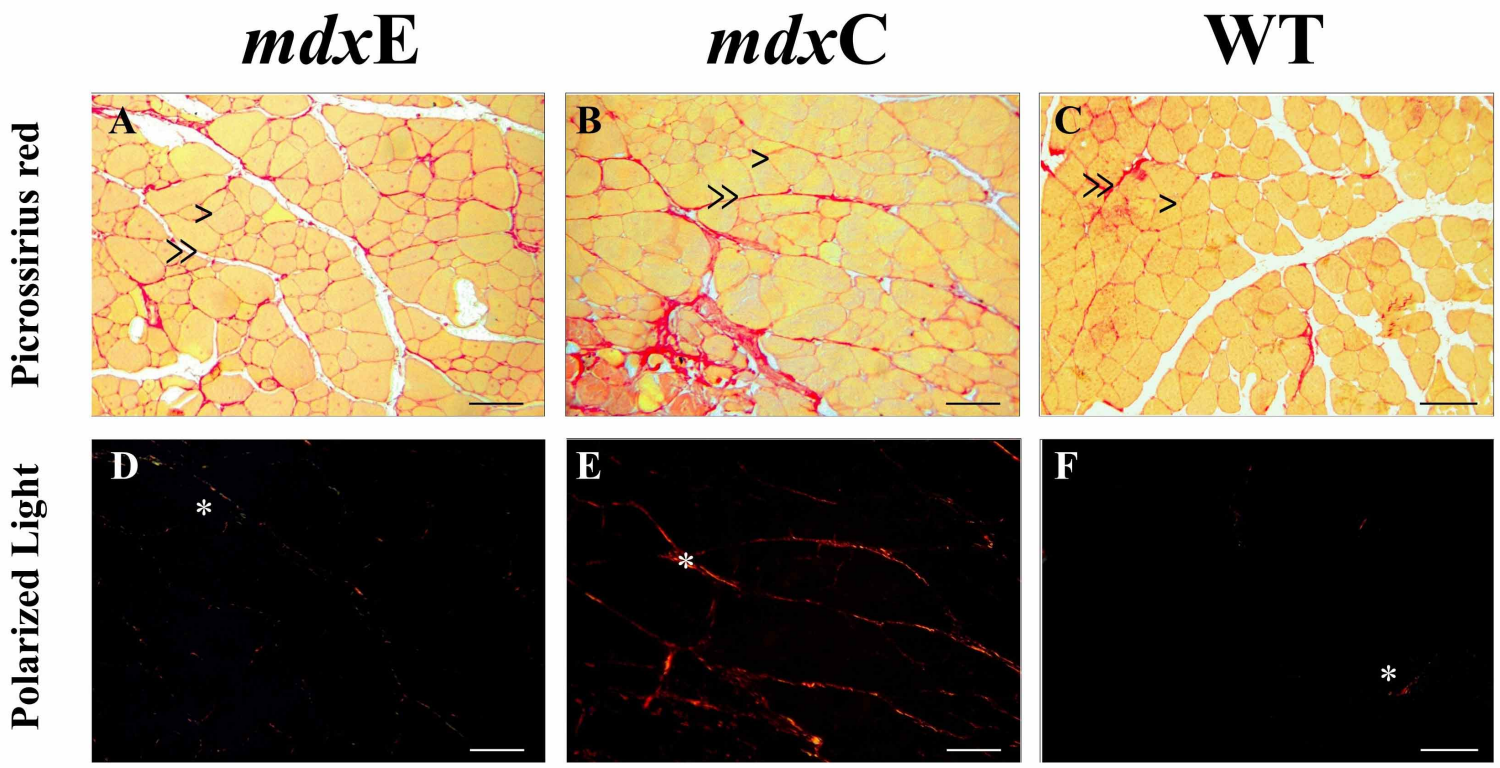

Fig. 4. Histochemical reaction with picrossirius red (A, B and C) and photomicrographs under polarized light (D, E and F) of gastrocnemius muscle of mdxE, mdxC and WT animals, 100x. On A, B, C, D, E and F: > collagen fibers at endomysium and $>$ collagen fibers at perymisium. * represent tracts of collagen fibers. Bar $=100 \mu \mathrm{m}$.

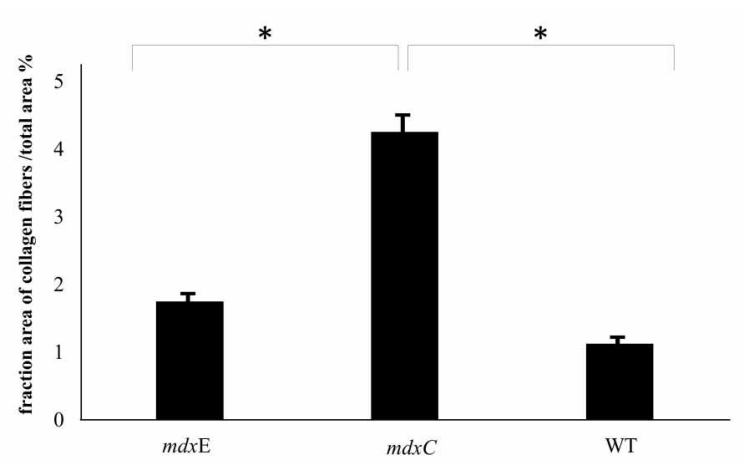

Fig. 5. Quantification of intramuscular collagen fiber deposition of mdxE, mdxC and WT groups. Mean values of $\mathrm{mdxC}$ are statistically different from mean values of mdxE and WT groups. *Mean values are statistically different at $5 \%$ attested by Anova, post-hoc Bonferroni.
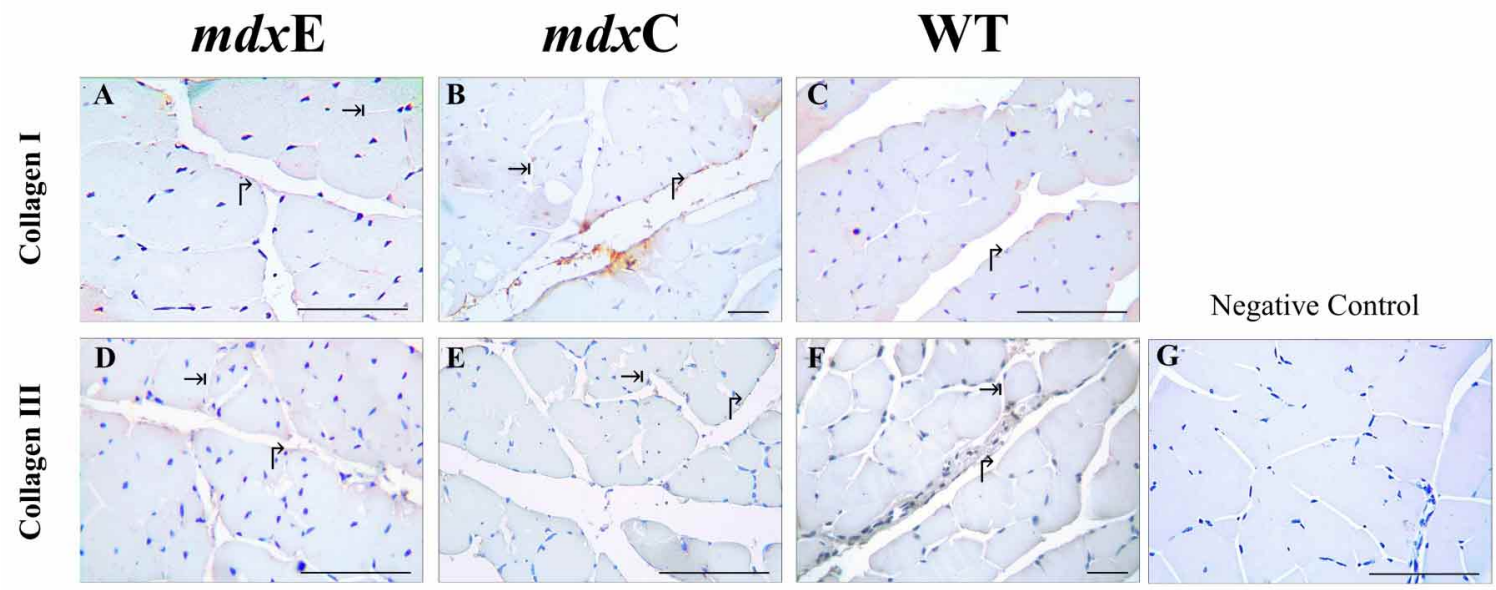

Fig. 6. Morphological analysis of gastrocnemius muscles of mdxE, mdxC and WT groups at 60 days of LIT protocol, 400x, IHC; immuno-localization of Type I (A, B and C) and Type III (D, E and F) collagen and negative control of immunohistochemical reaction in WT animal muscle $(\mathrm{G})$. On A, B, C, D, E and F: $\mapsto$ Immunolocalization of collagen fiber in perimysium. $\rightarrow$ Immunolocalization of collagen fiber in endomysium. Bar: $100 \mu \mathrm{m}$. 
fragmented sarcoplasm, inflammatory cells (Radley-Crabb et al., 2012), higher muscular fibrosis area and increased collagen fibers Type I (Pessina et al., 2014) on exercised mdx mice.

Until we know, few studies have investigated the low intensity treadmill training (Faist et al., 2001; Kaczor et al., 2007) and they have shown that this modality and intensity of training was physiologically beneficial to the $\mathrm{mdx}$ mice model.

Recent studies using other modalities of nonvoluntary exercise training, as Rota-rod and swimming, have also shown beneficial effects on dystrophic muscle. They described reduction of necrotic and inflammatory infiltrate areas (Frinchi et al., 2014), modulation of antioxidant enzymes (Fontana et al., 2015) and reduction of skeletal dystrophic muscle inflammatory process of mdx model (Hyzewicz et al., 2017). The results of these researches reinforces that modalities of non-voluntary training and of low intensity can bring beneficial responses of the dystrophic muscle of the mdx model even though few of them have investigated morphological parameters of the dystrophic muscle.

Our results show that animals that underwent on LIT treadmill training showed similar amount of centrally located nuclei fibers and similar variability of the muscle fiber diameter, both markers of muscle injury (Briguet et al.; Dubach-Powel) to the ones of sedentary dystrophic animals. Morphologically we can see that skeletal muscle of sedentary mdx animals presented inflammatory infiltrate areas and necrotic fibers that were not seen on exercised mdx animals. Moreover, the amount of intramuscular fibrosis area of sedentary mdx animals are similar to the ones already described to mdx mice at this age (Salimena et al., 2004). On the other hand, exercised mdx animals showed similar values to wildtype animals and significantly lower values than the mdx that have not underwent LIT training. This result of higher intramuscular area of sedentary mdx animals reflects the aberrant repair process of the dystrophic muscle tissue which presents higher deposition of connective fibers and leads to a non-functional tissue (Serrano \& Muñoz-Cánoves).

Fibrosis is a final result of a chronic inflammatory process on dystrophic muscle due to the absence of dystrophin (Smith \& Barton; Fontana et al., 2015). We have shown that this modality and intensity of training affected the intramuscular fibrosis in a beneficial way but further investigations are required to explain if LIT has delayed the formation of an intramuscular fibrosis or if it was reorganized by the contraction-induced adaptations on skeletal muscle tissue.
Regarding the type of collagen fiber deposition on intramuscular fibrosis, collagen Types I and III are located on the same tissue in different proportion which defines the features of the tissue (Mackey et al.). Collagen fibers Type III are observed during the regeneration process of the skeletal muscle (Mackey et al.) and these fibers were observed in sedentary and exercised animals at endomysium and perimysium. It shows that regeneration process as the markers of muscle injury was not directly affected by the LIT training here employed. Different from collagen fibers Type III, collagen fibers Type I that is commonly observed at the end of the muscular regeneration process and have a lower flexibility feature (Lieber \& Ward, 2013), was seen in both dystrophic groups but stained thinner tracts on endomysium muscle fibers of exercised mdx animals.

LIT treadmill training has no significant influence on lesion injury markers of gastrocnemius dystrophic muscle, once the process observed was the same on sedentary and exercised animals. The presence of inflammatory infiltrate and necrotic cells on sedentary mdx animals muscle could lead to the higher amount of intramuscular fibrosis detectable at the end of the experimental protocol. The immunolocalization of collagen fibers Type I and III was the same on both dystrophic groups and the feature of thinner tracts of the collagen fibers I reinforce the mainly found of this investigation that shows that LIT training affected dystrophic gastrocnemius muscle in a beneficial way.

Low intensity training provoked positive effects on gastrocnemius muscle of mdx mice model once it had reduced the intramuscular fibrosis deposition and had not exacerbated the markers of muscle injury.

PINTO, P. A. F.; MACHADO, A. S. D.; LIBÓRIO, L. R.; SANTOS, A. P.; OLIVEIRA, M. X. \& GAIAD, T. P. El entrenamiento de baja intensidad provoca adaptaciones en la fibrosis muscular de un modelo de distrofia muscular. Int. J. Morphol., 36(2):471-477, 2018.

RESUMEN: La distrofia muscular de Duchenne (DMD) es un trastorno neuromuscular genético con signos clínicos progresivos hasta la muerte, alrededor de la segunda década de la vida. Mdx es el modelo animal más utilizado para estudios preclínicos de DMD. Los parámetros del ejercicio en esta enfermedad muscular aún se desconocen. Esta investigación tuvo como objetivo investigar si el entrenamiento de cinta de baja intensidad exacerbaría los marcadores de lesión muscular, fibrosis y la composición de la matriz extracelular por colágenos tipo I y III del modelo mdx. Ratones machos de 11 semanas de edad con distrofia se separaron en grupos ejercitados ( $\mathrm{mdxE}, \mathrm{n}=8$ ) $\mathrm{y}$ sedentarios $(\mathrm{mdxC}, \mathrm{n}=8)$. Se usaron ratones de tipo salvaje como control (WT, $\mathrm{n}=8$ ). El grupo sometido a ejercicio se sometió a un protocolo LIT (9 m / min, $30 \mathrm{~min}, 3$ días / semana, 60 días) en una cinta de trotar horizontal. El músculo gastrocnemio se retiró el día 60 y se procesó para realizar análisis morfológicos y morfométricos. Los animales sedentarios mdx presentaron infiltrado inflamatorio y fibras 
necróticas. El análisis histoquímico reveló que el perimisio del grupo mdxC está organizado en fibras de colágeno gruesas y agrupadas, lo que genera una mayor área de fibras de colágeno intramusculares para estos animales. La histomorfometría indicó que el área de fracción de las fibras de colágeno del grupo $\mathrm{mdxC}$ era más alta que el grupo $\mathrm{mdxE}$ $(\mathrm{p}=0,04)$ y los valores del grupo mdxE eran similares al grupo WT $(p$ $=1,00)$. Las fibras de los núcleos ubicados centralmente y el coeficiente de varianza (VC) del diámetro mínimo de Feret fueron similares en los grupos mdxE y mdxC $(\mathrm{p}=1,00)$ y ambos grupos presentaron valores medios más altos que el grupo WT $(\mathrm{p}<0,00)$. La inmunohistoquímica reveló la presencia de colágeno tipo I principalmente en el grupo mdxC. El protocolo LIT no había agravado las lesiones musculares resultantes de la fragilidad de la membrana con deficiencia de distrofina al mismo tiempo que había reducido la deposición intramuscular de colágeno. LIT ha influido positivamente en estos marcadores de lesión muscular distrófica en el músculo gastrocnemio del modelo mdx.

PALABRAS CLAVE: Distrofia Muscular de Duchenne; Ejercicio; Músculo Esquelético; Colágeno.

\section{REFERENCES}

Barnabei, M. S.; Martindale, J. M.; Townsend, D. \& Metzger, J. M. Exercise and muscular dystrophy: implications and analysis of effects on musculoskeletal and cardiovascular systems. Compr. Physiol., 1(3):1353-63, 2011.

Briguet, A.; Courdier-Fruh, I.; Foster, M.; Meier, T. \& Magyar, J. P. Histological parameters for the quantitative assessment of muscular dystrophy in the mdx-mouse. Neuromuscul. Disord., 14(10):675-82, 2004.

Capogrosso, R. F.; Mantuano, P.; Cozzoli, A.; Sanarica F.; Massari, A. M.; Conte, E.; Fonzino, A.; Giustino, A.; Rolland, J. F.; Quaranta, A.; De Bellis, M.; Camerino, G. M.; Grange, R. W. \& De Luca, A. Contractile efficiency of dystrophic mdx mouse muscle: in vivo and ex vivo assessment of adaptation to exercise of functional end points. J. Appl. Physiol. (1985), 122(4):828-43, 2017.

de Brito, M. K. M.; Camargo Filho, J. C. S.; Vanderlei, L. C. M.; Tarumoto, M. H.; Dal Pai, V. \& Giacometti, J. A. Geographical dimensions of fibers from the soleum muscle in rats exercised on treadmill: the importance of the analysis by means of digitalized images. Rev. Bras. Med. Esporte, 12(2):103-7, 2006.

Dubach-Powell, J. DMD_M.1.2.001: Quantitative determination of muscle fiber diameter (minimal Feret's diameter) and percentage of centralized nuclei. Washington D. C., Wellstone Muscular Dystrophy Center, TREAT-NMD Neuromuscular Network, 2014.

Faist, V.; König, J.; Höger, H. \& Elmadfa, I. Decreased mitochondrial oxygen consumption and antioxidant enzyme activities in skeletal muscle of dystrophic mice after low-intensity exercise. Ann. Nutr. Metab., 45:58-66, 2001.

Fontana, S.; Schillaci, O.; Frinchi, M.; Giallombardo, M.; Morici, G.; Di Liberto, V.; Alessandro, R.; De Leo, G.; Perciavalle, V.; Belluardo, N. \& Mudò, G. Reduction in mdx mouse muscle degeneration by lowintensity endurance exercise: a proteomic analysis in quadriceps muscle of exercised compared with sedentary mdx mice. Biosci. Rep., 35(3): $000213,2015$.

Frinchi, M.; Macaluso, F.; Licciardi, A.; Perciavalle, V.; Coco, M.; Belluardo, N.; Morici, G. \& Mudò, G. Recovery of damaged skeletal muscle in mdx mice through low-intensity endurance exercise. Int. J. Sports Med., 35(1):19-27, 2014.
Gianola, S.; Pecoraro, V.; Lambiase, S.; Gatti, R.; Banfi, G. \& Moja, L. Efficacy of muscle exercise in patients with muscular dystrophy: A systematic review showing a missed opportunity to improve outcomes. PLoS One, 8(6):e65414, 2013.

Grounds, M. D.; Radley, H. G.; Lynch, G. S.; Nagaraju, K. \& De Luca, A. Towards developing standard operating procedures for pre-clinical testing in the mdx mouse model of Duchenne muscular dystrophy. Neurobiol. Dis., 31(1):1-19, 2008.

Holland, A.; Murphy, S.; Dowling, P. \& Ohlendieck, K. Pathoproteomic profiling of the skeletal muscle matrisome in dystrophinopathy associated myofibrosis. Proteomics, 16(2):345-66, 2016.

Hyzewicz, J.; Ruegg, U. T. \& Takeda, S. Comparison of experimental protocols of physical exercise for mdx mice and Duchenne muscular dystrophy patients. J. Neuromuscul. Dis., 2(4):325-42, 2015.

Hyzewicz, J.; Tanihata, J.; Kuraoka, M.; Nitahara-Kasahara, Y.; Beylier, T.; Ruegg, U. T.; Vater, A. \& Takeda, S. Low-intensity training and the C5a complement antagonist NOX-D21 rescue the mdx phenotype through modulation of inflammation. Am. J. Pathol., 187(5):1147-61, 2017.

Kaczor, J. J.; Hall, J. E.; Payne, E. \& Tarnopolsky, M. A. Low intensity training decreases markers of oxidative stress in skeletal muscle of mdx mice. Free Radic. Biol. Med., 43(1):145-54, 2007.

Lieber, R. L. \& Ward, S. R. Cellular mechanisms of tissue fibrosis. 4. Structural and functional consequences of skeletal muscle fibrosis. Am. J. Physiol. Cell Physiol., 305(3):C241-52, 2013.

Mackey, A. L.; Donnelly, A. E. \& Roper, H. P. Muscle connective tissue content of endurance-trained and inactive individuals. Scand. J. Med. Sci. Sports, 15(6):402-8, 2005.

Mann, C. J.; Perdiguero, E.; Kharraz, Y.; Aguilar, S.; Pessina, P.; Serrano, A. L. \& Muñoz-Cánoves, P. Aberrant repair and fibrosis development in skeletal muscle. Skelet. Muscle, 1(1):21, 2011.

Manning, J. \& O'Malley, D. What has the mdx mouse model of Duchenne muscular dystrophy contributed to our understanding of this disease? J. Muscle Res. Cell Motil., 36(2):155-67, 2015.

Nakamura, A. \& Takeda, S. Mammalian models of Duchenne muscular dystrophy: Pathological characteristics and therapeutic applications. $J$. Biomed. Biotechnol., 2011:184393, 2011.

Pessina, P.; Cabrera, D.; Morales, M. G.; Riquelme, C. A.; Gutiérrez, J.; Serrano, A. L.; Brandan, E. \& Muñoz-Cánoves, P. Novel and optimized strategies for inducing fibrosis in vivo: focus on Duchenne Muscular Dystrophy. Skelet. Muscle, 4:7, 2014.

Radley-Crabb, H.; Terrill, J.; Shavlakadze, T.; Tonkin, J.; Arthur, P. \& Grounds, M. A single $30 \mathrm{~min}$ treadmill exercise session is suitable for 'proof-of concept studies' in adult mdx mice: a comparison of the early consequences of two different treadmill protocols. Neuromuscul. Disord., 22(2):170-82, 2012.

Salimena, M. C.; Lagrota-Candido, J. \& Quírico-Santos, T. Gender dimorphism influences extracellular matrix expression and regeneration of muscular tissue in mdx dystrophic mice. Histochem. Cell Biol., 122(5):435-44, 2004.

Serrano, A. L. \& Muñoz-Cánoves, P. Fibrosis development in early-onset muscular dystrophies: Mechanisms and translational implications. Semin. Cell Dev. Biol., 64:181-90, 2017.

Smith, L. R. \& Barton, E. R. Collagen content does not alter the passive mechanical properties of fibrotic skeletal muscle in mdx mice. Am. J. Physiol. Cell Physiol., 306(10):C889-98, 2014.

\section{Corresponding author:}

Thaís P. Gaiad

Rodovia MGT 367 - Km 583, n 5000

Alto da Jacuba CEP 39100-000

Diamantina, Minas Gerais - BRAZIL

Email: thaispgm@gmail.com

Received: 23-10-2017

Accepted: 27-01-2018 